\title{
How the Poet Soars into Devotional Ecstasy in Crossing the Bar- A Rhetorical Study
}

\author{
Priyanka Dey \\ Asst. Professor (English), Department of Applied Science, Haldia Institute of Technology, WB, India
}

\begin{abstract}
Lord Alfred Tennyson silhouetting the "intellectual throne" of Victorian England with his entire blaze is often called a "poetic stylist". Starting his poetic journey from 1829 with Timbuctoo he wrote different kinds of poetry some of which were gay, some serious, some flippant, a lot many passionate, some with a note of lamentation and a large number sensuous. But as his life and poetic career gradually rolls on like the rising sun across the sky with time he gains the inevitable maturity and deeper insight into the cosmic evolutionary process. His poems from mere sensuousness attain a devotional note of complete spiritual surrender at the feet of his "Pilot" and his yearning to unite with Him intensifies. He wins over the fear of death and dissolution; his poems from the elegiac note of Break, Break, Break transcend into an ecstatic mood in Crossing the Bar which he wanted to be inscribed as an epitaph on his sepulchre. But it is through the coalescence of form and function this total transcendence in thought, feeling and attitude to life succeeds in finding expression. Hence in this paper through the stylistic analysis of Crossing the Bar an attempt is made to study the poetic diction and versification, the rhetoric profile that enables the poet to create a milieu perfect for his heightened realization.
\end{abstract}

Key words: allegory, lexical cohesion, metaphor, nominalization, parallelism, prosody, verbal style, etc.

\section{Introduction}

A language comprises discourses, a discourse comprises dialogues, a dialogue comprises sentences, a sentence comprises words and a word comprises sounds. These units which make up the phonological structure of the language have no independent function of their own "but serve only to construct units of grammar" [Widdowson, 1975, 58]. Stating simply, these sounds themselves become full of significance when framed in words. But when we read poetry the first thing or element that captivates our heart and transcends us instantly to another world is the enigma of rime and rhythm being created by the variedly patterned but sounds. The sound patterns are so devised by the writers that they crossing the domain of mere word constructs enter directly into the meaning investing the lexical items with some such values which they would otherwise not have. However, as mentioned at the very outset, words formed from typically arranged sounds do not render the complement to the language, and hence, to the cumulative effect which the writer expresses or implies. These words further through permutation and combination are organized into some unique patterns so that the literary language bestows a semantic value on the linguistic elements constituting them thereby producing the total impression of the intended concept. These arrangements vary from individual to individual and fosters the birth of what we call rhetoric profile of diverse types.

Rhetoric profile thus is "established primarily by the quality of diction, the general structure and length of sentences, the structure and the length of paragraphs and the quantity of metaphor and other poetic devises"[Weathers and Winchester, 1967, 127]. It is therefore, by virtue of this that some compositions can arouse some inexplicable sensation, in someone can evoke the feel of

$$
\begin{gathered}
\text { A presence that disturbs me with the joy } \\
\text { Of elevated thoughts; a sense sublime } \\
\text { Of something far more deeply interfused, } \\
\ldots . . . . . . . . . . . . . . \\
\text { A motion and a spirit, that impels } \\
\text { All thinking things, all objects of all thought, } \\
\text { And rolls through all things. }
\end{gathered}
$$

[Tintern Abbey: Wordsworth]

\section{Rhetoric and style}

In Greek history, as states the Encyclopedia of Rhetoric (ed. Sloane,2001) the usage of rhetoric dates back to $5^{\text {th }}$ century bce and in India it's even earlier- in the Sanskrit traditions, the Vedas and the Upanishads, 
c.2000 bce. However, whether it be oriental or occidental the approach of the scholars in both the cultures and their understanding of the subject was not marked by gulf-wide distinction. All of their applications ascertain the fact that rhetoric comes into being when a rhetorician observes or creates an exigency and offers discourse designed to bring the interests of the audience to bear on it. In essence, then, the addresser (the writer/the poet) addresses some or all parts of the rhetorical situation - the audience and the constraints available to them; the discourse, message, or symbols used to address the exigency; how the urgency of the situation itself is built, developed, created, and addressed; and the larger contexts-historical, social, economic, cultural, and symbolic - in which the situation is playing out. This (s)he achieves deploying various tropes and figures which are being represented in a way conforming to the pulse of the situation or the psychological construct of the composer thereby giving rise to a distinct style. Hence rhetoric and style seems to be the two legs of a compass each complementing the other.

\section{Classical Rhetoric and the Contemporaries}

The word rhetorike in Greek recorded literature first appears in Plato's Gorgia's [449a5] which was written probably about 385 bce [Sloan ed., Aug 2001, 105]. It is a dialectic conversation mainly between his master Socrates and Gorgias, the Sophist, on the concept of rhetoric. There we observe while for Gorgias rhetoric is "a tool of power and pleasure" [Scott, 1984, 1], Socrates considers persuasion besides causing beliefs also produces knowledge- "He must create a context which does not notice words as word". [Lanham, 1976, 38]. To Socrates meaning stands supreme while to Gorgias it is the way of patterning the words and delivering them. Thus Neel argues that for Plato "There is nothing wrong with style, of course, just so long as it comes after and remains subservient to matter, which alone can be "true"" [Neel, 1988]. But Aristotle took a middle path. George Kennedy the translator of Aristotle's On Rheotric writes "The concept of a mean between extremes is characteristic doctrine of Aristotelian ethics that finds application to rhetoric as well" [Aristotle, 1991, 91]. Aristotle, in his lectures on public speaking adopted the word Rhetoric as "descriptive of the subject, both generally and specifically". [ibid, 109]. In Book 1 and 2 Aristotle is mainly concerned with what he calls dianoia "thought" that is the content of the speech. This later came to be known as rhetorical invention. To him rhetoric was the means of persuasion and Aristotle believed that "language cannot achieve its function if it is not clear, and it will not persuade if it is not appropriate" [Murphy, 1995, 103]. He recognizes three artistic forms of persuasion - logos(the appeal to reason), pathos(the appeal to emotion) and ethos(the persuasive appeal of one's character) and three genres of civic rhetoric-forensic(or judicial), deliberative(or political) and epideictic (or ceremonial).

Aristotle's Book 3 On Rhetoric dedicates eleven chapters [2-4 and 5-1] to the discussion of the style or 'lexis' where he elaborately talks about diction, word choice, and sentence composition with an aim of evoking the appropriate emotional response in the audience and inducing its trust in the composer's (/speaker's) good sense, good will, and virtue. There he defines style as the "virtue" (a word self-sufficient enough to consummately translate all that the Greeks comprehended under the term arete.) of clarity, as an element of rhetoric "neither flat nor above the dignity of the subject" [Aristotle, 1991, 221]. It is the strategic choice that strongly influences the rhetorical situation. Thus, for Aristotle a good style in rhetoric states the qualities of conciseness and appropriate choice. He focuses mainly on the statement and confirmation deeming them indispensable aspects of speech. However, for Cicero elegance in oratory is of prime importance. He believed,

"As a matter of fact, the art of delivering a beautiful oration in an effective oratorical style is nothing else...than presenting the best of thoughts in the choicest language. Furthermore, there is no thought which can bring credit to an orator unless it is fitly and perfectly expressed, nor is brilliance of style revealed unless the words are carefully arranged. And both thought and diction are embellished by rhythm" [Cicero, 1939, 499].

Cicero describes good style as the benchmark distinguishing good writers from bad on the basis of harmony, grace, craftsmanship and polish. But he places knowledge, above rhetoric or the stylistic choices with the admonition, "if the underlying subject matter be not comprehended and mastered by the speaker" the oration how much ornamented "be of no account or even become the sport of universal derision". [Cicero, 1959, 1, 39]. However, later he puts equal emphasis on style and adornment when he explicates that the traits of ornamentation and appropriateness means that style "must be in the highest degree pleasing and calculated to find its way to the attention of the audience and that it must have the fullest possible supply of facts [3.73]. Quintilian to whom rhetoric was bene dicendi scientia meaning "the science of speaking well" [2.15.34] also holds similar opinion. In Book 1 Institutio Oratoria he says, "all grammar has three kinds of excellence, to be correct, perspicuous, and elegant" [1.5.1]. He considered that "embellishment is what most distinguishes each individual orator's style" but adds that "amplification, sentential epigrams, and tropes such as metaphor, allegory, and irony should all be used but sparingly" [Bizel and Herzberg, 2001, 296]. Quintilian was quite 
aware of the need for balance in levels of style and therefore, suggests that "style need not always dwell on the heights: at times it is desirable that it should sink. For there are occasions when the very meanness of the words employed adds force to what we say" [8.3.21]. According to Quintilian a success in the oratory lies in the amplification or the attenuation of the force of the "words employed to describe a thing" [8.5.90] and his method of amplifying is being accomplished through copia- "abundance" one achieves through the exploitation of stylistic resources-

"There can be no doubt that he must accumulate a certain store of resources, to be employed whenever they may be required. The resources of which I speak consist in a copious supply of words and matter" [10.1.5].

Thus simplicity or lucidity, correctness and elegance frames Quintilian's concept of style too. But at the same time he acceded to the fact that an individual or distinct style is being created through the exploitation of words. "Style and invention" was perceived by him "as part of an organic process" and he used it "to train Roman orators beginning when they were young" [Butler, 2008, 43].

All these classical rhetoricians, hence, defined style in terms of its functions. Their thought was influenced greatly by the Latin rhetorician's system of status- a term involving three Latin phrases: an sit (whether the thing is), quit sit (what the thing is), and quale sit (what is its quality). "In other words, did the cause turn on a question of fact (did Antony kill Caesar?); or on a question of definition (yes, Antony killed Caesar, but was it murder?); or on a question of quality (yes, Antony murdered, but was this act good or bad?)" [Corbett, $C C C$ 14,163]. The classical rhetoricians through the recognition that the speaker and the spoken to are multifarious tried to make better provisions for bringing "the whole soul of man into activity". But the contemporary definition of rhetoric tries to define style in terms of its boundaries. [Mohrbacher, Minnesota English Journal 8, 9].

Louis T. Milic writes in Theories of Style and Their Implications that "There are only three theories of style though there has been much embroidery over the basic fabric" and he categorizes them as-

- "Rhetorical dualism" or the theory of ornate form which implies that "words exist worldlessly and can be dressed in a variety of outfits, depending on the need for the occasion: the grand style, the plain style, the middle style and the low style and the like."

- Individualist or psychological monism which celebrates the dictum "style is the man", and it might have had its origin, according to Louis, in Plato's conception of vir bonus- the sobriety and the virtues of a good person would get expressed through his movements and expressions. The modern version of this "psychological monism" however holds the idea of writing in one's own way, in a way that comes out naturally, spontaneously condemning all pessimistic criticism. Louis feels this modern version to have descended from Montaigne.

- Crocean aesthetic monism which expounds the prevailing definition of style discarding the difference between form and content. Milic calls it an organic view that sees "work of art is a unified whole" where "there is no style at all, only meaning or intuition" [Milic, CCC vol.16.2, 67]

Richard Ohmann too believes "A style is a way of writing" [Ohmann, 1970, 259]. Mohrbacher infers in Style: Definition, Separation, and the Teachable that for Ohmann the boundary lines are not a matter of great concern. For him "the style is born out of "intuition" [Mohrbacher, Minnesota English Journal 8, 9]. Ohmann takes in the matters of correctness and arrangement in the realm of style but says, "though syntax seems to be the central determinant of style, it is admittedly not the whole" [Ohmann, 1970, 276].

In "Grammars of style" [1990] Winston Weathers while discussing about style writes "grammar of style" is a set of conventions governing the construction of a whole composition; the criteria by which a writer selects the stylistic materials, methods of organization and development, compositional pattern and structure he is to use in preparing any particular composition. This seems to be an echo of the approach found in Becker and Pike's contention that style is an indispensable part of the "universe of discourse"-

"A writer's style, we believe, is the characteristic route he takes through all the choices presented in both the writing and prewriting stages. It is the manifestation of his conception of the topic modified by his audience, situation, and intention-what we might call his "universe of discourse"”' [Young and Becker, 1967, 140].

In Rhetoric and Style: Strategies for Advanced Writers Nevin Laib defines style as the "external expression of your values and beliefs, your personal or social rhetoric" [Laib, 1993, 21]. He says that, in the selection of the grammatical elements, the contents, the words, in the manner of giving vent to one's emotions 
those values and ethical sense of the individual get manifested. Hence the authors, according to Laib, must in a tactful way arrange or use those elements in constructions so that the created style makes him an "admirable" dignitary.

\section{Crossing the Bar-Rhetoric Profile}

Jan Mukarovsky, one of the prominent figures of Prague Linguistic Circle in his famous essay "Standard Language and Poetic Language" writes that poetic (that is, literary) language is "an aesthetically purposeful distortion of standard language" [Freeman ed., 1970,6]. Poetic language intentionally "breaks the rules in order that a given passage be noticed as language" [ibid]. And different kinds in a varying degree make a sincere practice of deviating from the rules of grammar. Since the deviation is a purposeful act there must be some logic behind this motivation, a context guiding the situation. Tennyson in Crossing the Bar should also therefore stand no exception to it. Indeed he does not. At various level (such as Syntax, Phonology, Morphology) various rhetorical devices he deploys indicates how the writer takes himself and what he is saying. It is but the mind skating circles around itself as it moves forward. Every rhetorical detail explicated below attests to the statement of fact.

IV(i) Structural features- The study of parallelism in the potentially rich rhetorical tradition dates back to the period of Aristotle's discussion of paired cola (paired phrases or sentences) as one which could produce an impression of segmented, equivalent units for a listener (Kennedy, 1991, 243) in book 3 of the Rhetoric. Parallel construction works on the principle that expressions of similar content and similar function should be outwardly similar. The likeness of forms (sharing same parts of speech) readily enables the listeners (/readers) to readily relate the similarity of the content with the function. In Crossing the Bar what we see is this syntactic pattern is the most recurring and dominant stylistic device exploited by the poet with maximum flamboyance-

And [one clear call for me!]

[may there be no moaning...to sea,]

And [after that the dark!]

[may there be no sadness of farewell,...embark]

Too [full $\{$ for (sound and foam) $\}]$

(since the Deep structure is -'Too full for sound and too full for foam')

For tho' from out our bourne of [Time and Place]

In fact the pattern of the first stanza [L1-L4] and second stanza [L5-L8] reiterates in the third [L9-L12] and fourth [L13-L16] stanzas. A closer look tells that all the stanzas are wholly balanced on an equivalent structure and that symmetry which may be shown schematically-

L1//L9 = "Sunset and evening star" // "Twilight and evening bell"

$\mathrm{L} 2 / / \mathrm{L} 10=$ "And one clear call for me!" // "And after that the dark!"

L3//L11 = "And may there be no moaning," // "And may there be no sadness of farewell,"

L4//L12 = "When I put out to sea," // "When I embark,"

$\mathrm{L}[5-6] / / \mathrm{L}[13-14]=$ "But (connective-coordinate) such a tide as moving ...foam ," // " For tho" (connectivesubordinate) from out our ....me far,"

L7//L16 = "Turns again home" // "I hope to see my Pilot face to face"

L8//L15 = "When that which drew from out the boundless deep"// "When I have crost the bar."

[Note-:// = parallel sign]

So not only the 1-2 stanzas and 3-4 stanzas exhibit parallelism in construction, as a matter of fact, with careful observation it is found that the structural cohesiveness between the coupled stanzas have also been engendered by the poet deploying parallelism with a twist in the last two lines [L7 \& L8] of second and fourth [L15 \& L16] as shown above. It is only in the last two lines that a return to the norm is being felicitated; else no where there is an infraction of this regular pattern. Even the punctuations along with the lines show brilliant equivalence thereby making the truest application of parallelism perhaps in the ever possible best sense in every aspect leaving no stone untouched. Parallelism followed with sincerest sincerity shows that the pattern of the poem is no casually or whimsically arranged one, rather thoughtfully contrived for artistic expressivity. In fact this is how the "poetic grammar" is being devised in the poem concerned for the purpose of the aesthetic effect. But too much adherence to the grammar also at times acts as an obstacle to the flow and disturbs the poetic appeal rather than fostering it. Hence the change in pattern in the last two lines L15 and L16. Had this specific deviation (i.e parallelism) maintained with specific regularity throughout the poem not been breached with a 
return to the grammatical norm (regularity) of standard language the intended poetic situation could have not been evoked or the relations defined by the "grammar" of a poem what Richard Ohmann says "cognitive orientation", been successfully conveyed to the readers. Having the monotony broken in this way particularly in these two lines the poet actually foregrounds his thought. Such a jolt in the otherwise smoothly running stanzas reflects the sudden awakening of the poet's soul to the inner realization that this journey to the sea leaving the earthly life is indeed the journey to his heavenly abode, a even happier life where he hopes "to meet his Pilot face to face". The recurrence of the similar pattern explicates the untiring attempt of the poet to uproot the sense of insecurity and skepticism enshrouding (the life of) his age by his enlightening spiritual philosophy of life and its origin, birth and rebirth which was greatly threatened by the upheaval of science and revolutionary theory of Darwin and the like. Repeating the pattern through structural equivalence he actually endeavors to nail in this concept of the cyclic process of life, the causal-effect phenomenon to which the whole cosmic-universe is fulcrum-set.

IV(ii) Prosodic view- Here we find that the poem is composed with ABAB CDCD EFEF GAGA rhyme scheme in iambs in which the stress occurs at every regular interval starting with a fall in the initial position. Language has two levels viz. deep and surface syntactic structure. The semantic interpretation proceeds from the deep structure while the phonetic interpretation from surface structure. These two levels are related by an ordered set of transformation(s) which are meaning preserving. So the different arrangement of sounds, words and phrases or clauses that are being made by the poets or writers are the result of exploitation of the selective transformations that the composer applies to produce the desired aesthetic effect. Given to this fundamental linguistic theory working as an undercurrent behind the selection and arrangement at every level, we can certainly infer that Tennyson for some definite reason out of the four base feet viz,- iambus, trochee, anapaest and dactyl chooses only the first rising feet (iambus) to compose his verse. In the poem such a splendid regular rhythmic pattern has been maintained which is a rare spectacle to enjoy. But it is found that the stress falls without a tinge of irregularity only on those words which act as a vehicle to propagate his notion of belief-

(Sun)-se't, e've-(ing) [2], sta'r, o'ne, ca'll, me', ma'y [2], be' [2], mo'an-(ing), o'f [2], ba'r [2], I' [3], o'ut [3], se'a, su'ch, ti'de, mo'v-(ing), se'ems, (a)-sle'ep, fu'll, so'und, fo'am, tha't [2], dre'w, bo'und, de'ep, a'-(gain), ho'me, (twi)-li'ght, be'll, a'f-(ter), da'rk, sa'd-(ness), (fare)-we'll, e'm-(bark), tho'”, bo'urne, Ti'me, Pla'ce, flo'od, be'ar, fa'r, ho'pe, se'e, Pi'-(lot), fa'ce [2], cro'st.

The accented words so marked attest to the fact that just to emphasize on his thought he chooses this pattern. He does not want the reader to leave any single line with focus on a word not propounding his theology or spiritual belief that though the earthly life is perishable and veiled in illusion, there is a Being beyond all these meretricious manifestations of illusion, who is superior to and independent of it, and who is attracting all of us towards himself, and that we are all going towards him. Tennyson seems to find answer to the ever aching questions of human life- what happens to man after death-

"What is this universe? From what does it arise? Into what does it go?" [Vivekananda, 1972, 64]

It dawns at him it is towards freedom-

"In freedom it rises, in freedom it rests, and into freedom it melts away" [ibid].

Thus the poet writes-

"And may there be no moaning of the bar,

When I put out to sea,

And may there be no sadness of farewell,

When I embark;

I hope to see my Pilot face to face

When I have crost the bar."

The beats at regular intervals echo the sense, illustrate the strong bonding between the phonetic and the semantic levels of the text manifested through the sounds. The acoustic image of (fall-rise) ${ }^{\prime}, v^{\prime}$, evoke a visual graph of the poet's pulsating heart now beating in confidence with all the complacency and peace overcoming all conflicts with the questions of origin and influence of materialism of the Victorian age. It 
reflects the lost Paradise of faith regained with the realization of "Religion begins where science ends" [Swami Ramkrishnananda: His life and legacy, 165-69] thereby establishing firmly the correspondence between sound and psychic reactions, that is between acoustic substance and the network of meanings and impressions. The framing of the last stanza with a repetition of the rhyme scheme of the first stanza renders the sense of completion to the poem with the fostering of an integrity between the thought expressed at the beginning with the thought asserted at the end. It binds the first with the last by falling on the ear with an echo.

IV(iii) Verbal nominalization- A quite prominent feature of the poem concerned is that its aversion to verbal style and affinity towards nominality. The whole poem reveals a reluctance of the poet to the use of so called finite verbs. Either the verb-less sentences are being projected or sentences with verbs nominalized used. In this sixteen lines poem we may note only 9 finite verbs have been exercised - be (2), put, seem, drew, turn, embark, bear, hope, crost- with a sincere repetition of some such verbs like the existential one "be". Of these nine verbs again seem unlike the others is not a control predicate that is cannot assign thematic role to its subject-it is an impersonal verb. The construct shows that the poet would rather go verb-less than using a finite verb. In the first two lines we find no verb at all which is again being repeated in the 3 -stanza.

"Sun-set and evening star,

And one clear call for me!'[L1-L2]

"Twilight and evening bell,

And after that the dark!" [L9-L10].

Even the verb "moan" [L-3] has been changed to its nominal form "moaning" and "move" [L6] to participle "moving". The reason behind this preference is the heightened universal theme of the poem i.e. eternity, timelessness. Finite verb not only carries number but person and tense. Aristotle distinguishes Greek verb from Greek noun on the basis of the presence or absence of tense marker [De Interpretetione 2.16a19, 3.16b6]. Whenever a writer attempts to flout the sense of time, he tends to avoid finite verb. Nominal style exhibits more spontaneity than verbal style and thus "it is natural for those who are more concerned with what they say than with how they say it" [T.A Sebeok, 1960, 217]. The very fact that the nominality is contrary to conversational style has considerable significance. It sets of the writing as esoteric, specialized. Besides nominal style, more than verbal style, promotes impersonality. In the sentences like "And may there be no moaning of the bar,", "And may there be no sadness of farewell" through nominalization (of verbs and adjectives respectively) the poet eschews personal projection; he attempts to capture the ethereal sensation through a universal phenomena of spiritual transcendence. This phenomenon for the poet is both the presence and the sense, motion and the spirit, an experience which is compounded of all the earthly things and at the same time manifested through each of them. The suggestiveness impinged into the poem through the word "may" arouses a fear of uncertainty about life after death and at the same time evokes expectation from the predictable world into uncertainty thereby involving the poet in the exploration of the ecstatic experience oozing out of these lines-

"For tho' from out our bourne of Time and Place

The flood may bear me far,

I hope to see my Pilot face to face

When I have crost the bar".

As the poem moves towards the end Tennyson gradually seems to take refuge at the verbal style. It is the realization of God's purposes in the human spirit as much as in the universe seem to have been dawned to the poet and thus with this introspection and meditation he opens the poem in a nominal style. However, in the course of his journey human life fettered by Time and Place further stirs the wave of disbelief trying to engulf his spirit along with the others'. His exploitation of verbal style in the poem hence is seen specially in those lines where he is trying to overcome his personal dilemma and hesitant thoughts about the end of life, the conflict between the age old faith and the revolutionary ideas, the ancient intellectual order and the new evolving theories in various spheres of knowledge, striving to triumph over the tug of war between skepticism and religious uncertainty, spiritual struggle and unrest, inquiry and criticism his (Victorian) age was circumscribed with. Moreover, these lines all being composed in active voice promotes the poet himself as the subject. This besides making the speech more personal instills greater vivacity and directness thereby enforcing the poet's nonequilibrium mental set. But the light of wisdom permeating from his Pilot into him outshines the dissuading forces. It urges the poet to outlive the years and makes him even ardent. It injects in him a sense of positivism and strengthens his zeal of tearing apart the shackles of physical bondage with all vigour and force being reflected in the verbal style of the closing lines of the poem- 
"I hope to see my Pilot face to face

When I have crost the bar." [L15-L16]

IV(iv) Lexical Cohesion- Cohesion in a text is brought about in a numerous ways. One is through the use of lexical item. They are manipulated with such amazing expertise that even the most insignificant word comes to attain the highest significance with a speculative interpretation of the text where it is used. Different figures of speech are being heralded. In Crossing the Bar the name of the poem verily expresses the most delicate allegory of the eternal journey of life. The living creature particularly human being with God-gifted intelligence and philosophy is adhered with the carnal attractions and pleasure all through heart and soul. But the life flows and rolls down to eternity leaving the possessor of life in dark of the sublime stream. This is the general truth. So a particular being when departs the others become mournful and sad farewell follows. The appearance of the final moment is symbolized by "Sunset and evening star" and the poem hails these as "one clear call for me". And here the poet expresses his desire that there should be "no moaning" for he realizes that he is starting for the divine journey. The waves of life as depicted, "tide as moving", but really it is "asleep"; apart from "sound and foam" the principal journey is nothing all these but turning "home". Again "Twilight and evening bell" having performed their duties simply inspires the poet to "embark" and the pleasant voyage beyond the "bourne of Time and Place" presents the poet before blissful heaven the God. Thus the long cherished passion traversing the earthly journey comes to the lap of God. God and "Pilot" expresses the sublime metaphor to create the devotional mood of rejoicing union.

Hence "Sunset", "evening star", “one clear call", "Twilight", “evening bell”, "dark"-the association of these lexical items in this context has the effect of activating those semantic features in their signification which have a common point of reference-the closing stage of earthly life. Moreover, these lexical items often being conjoined through polysyndeton instill an added momentum to the poem thereby strengthening further the underlying lexical bonds. The anaphoric deictics "that which"[L-7], "that"[L-10] used every now and then either to refer back to the "tide", the journey to his prenatal abode, Heaven, or to the alarming bell reminding him of his penultimate hour on earth intensify the contemplative mood running as an undercurrent from beginning till end. The poem opening with words and ideas co-ordinated by so many and-s and proceeding with "but", "as" creates an impression of the continuation of the trance like state the poet was in; these words breathes into it (the poem) the sense of sudden awakening from a dream one like Charles Lamb's Dream Children, the only difference between the two being Charles was dreaming of his could be earthly family there and Tennyson here meditating upon his heavenly relations (Pilot). Thus the exclamatory signs in the very opening sentence of the poem, inverting the order of 'drew out from the boundless deep' to "drew from out the boundless deep" [L7].We observe here the poet's vision is translatable into action. The poem mimetically evokes the active feeling of journeying out, of the exhilarating freedom of sailing out to sea with a hope to meet his Pilot through the imagery of sea, tide and Crossing the Bar. The "call" evokes both an enervating grief and an elevating grasp of an idea of spiritual and physical evolution. A shifting and developing perception as a mortal victim and an immortal spiritual pioneer runs through the poem. The poet seems to have realized the key to every creation and transcendence in the active participation in the continuing evolutionary process which links the material to the spiritual, the animal to the divine. There is no longer a recoil from natural flux, from geological change, from death or decay, rather an eagerness to set out.

\section{Conclusion}

Stylistic investigative process in Jakobsonian terms is concentration upon 'the 'set' towards the message" [T.A Sebeok (ed.), 1960, 356]. Given to this definition of stylistic analysis thus the apparatus facilitating linguistic description plays a very vital role in literary analysis, in deciphering the rhetoric profile of a poet reaching out to the inference of his philosophy of life often acting as a worthwhile food for thought and re-fabricating our life. Tennyson believed in what Keats writes-

"The genius of poetry must work out its own salvation in man. It cannot be matured by law and precept, but by sensation and watchfulness in itself. That which is creation is creation itself."

and it is often compared with the couplet from Pope

"Those rules of old discovered, not devis'd,

Are Nature still, but Nature methodis'd,"

[Hudson, 1961, 185] 
These sentiments only find their highest manifestation in the manifold of forms used in the poem. Poetry is often defined as strong feelings and emotions expressed through speeches or words patterned in multifaceted ways. Hence to decipher the style of a particular writer both intuitive literary judgment as well as objective linguistic analysis of techniques exploited to evoke various poetic effects needs to be taken into consideration simultaneously. A mature literary cum linguistic intuition provides clues, indicating certain linguistic features as pivotal in foregrounding certain thoughts and establishing a text's style. Thus one is dependent on the other.

Rhetoric profile, therefore, structures the backbone of any particular style. The function of linguistic description is not merely to give precision to the nature of the poetic features but ascertain the significant stylistic effects engendered and /or enhanced by them in the composition concerned in advance of careful analysis. Kroeber suggests, that "judgment, recognition of style is primary, analysis and statistics secondary."[Sebeok, 1960, 114] However, from the above analytical study of Crossing the Bar what comes out clearly is, it is equally important "to emphasize that a rigorous checking, by means of a description of a total complex of features possessed by the text, of features intuitively judged to be stylistically significant, is likely to uncover other, previously unobserved, significant features; or to demonstrate the inter-relationship of a series of features in such a way as to offer new, or at least modified, responses to the text as a whole. In this way our responses to the style of a text are open to progressive development. Only if we refuse to recognize the validity of responses which result from careful textual study,... can such development be regarded with suspicion.’[Freeman, 1970, 82-83]

\section{Reference}

[1] H.G. Widdowson, Stylistics and the teaching of literature (Longman Publishing Group, 1975) 58.

[2] Winston Weathers, and Otis Winchester, The new strategy of style (Mc Graw-Hill Book Company, New York, U.S.A., 1967$) 127$.

[3] Thomas O. Sloane, (Ed), Encyclopedia of rhetoric, e-reference edition, (Oxford University Press. The Midnight University, eISBN:9780195188448, 2006) 50, 105

[4] Frances Scott, Plato: Gorgias: study guide to arguments (Department of Philosophy. Texas Tech U, 1984) 1.

[5] Richard A. Lanham, The motives of eloquence: literary rhetoric in the renaissance (New Haven: Yale UP, 1976) 38.

[6] Jasper Neel, Plato, Derrida, and writing (Carbondale: Southern Illinois University Press, 1988).

[7] Aristotle, On rhetoric: a theory of civic discourse, Trans. George A Kennedy (New York: Oxford UP, 1991) 91, $109,221$.

[8] James J. Murphy, and A. Katula Richard (Eds), A synoptic history of classical rhetoric, 2 (Davies, CA: Hermagoras, 1995$) 103$.

[9] Cicero, Orator, Trans. H.M. Hubbell (Cambridge, MA: Harvard University Press 1939) 499.

-, De oratore, trans. E.W. Sutton Vol-1, bk-1, 2 (Cambridge, MA: Harvard University Press 1959) 39.

[10] Quintilian, Institutio oratoria, Trans. H.E. Butler (Cambridge, Mass., Harvard University Press. London, William Heinemann Ltd., 1920,1922).

[11] Patricia Bizzell and Bruce Herzberg (Ed), The rhetorical tradition: readings from classical times to the present, 2 (Boston: Berdford / St. Martin’s, 2001) 296.

[12] Paul Butler, Out of style: Reanimating stylistic study in composition and rhetoric (Utah University Press, Logan. Utah, 2008$) 43$.

[13] Edward P.J. Corbett, The usefulness of classical rhetoric, College Composition and Communication, $141963,163$.

[14] Carol Mohrbacher, Style: definition, separation, and the teachable, Minnesota English Journal 8, 9.

[15] T. Louis Milic, Theories of style and their implications for the teaching of composition, College Composition and Communication, 16(2), May 1965, 67

[16] Donald C. Freeman (Ed), Linguistics and literary style (Holt, Rinnehart and Winston, Inc., 1970) 259, 276, 6, 82-83.

[17] Winston Weathers, Grammars of Style: New Options in Composition. In Richard L. Graves (Ed), Rhetoric and Composition: a sourcebook for Teachers and Writers, 3 (Portsmouth, NH: Boynton/Cook-Heinemann, 1990) 200-14.

[18] Richard E. Young, and Alton L. Becker, Toward a modern theory of rhetoric: a tagmemic contribution (In Steinmann, 1967) 77107.

[19] Nevin K. Laib, Rhetoric and style: strategies for advanced writers (Upper Saddle River: Prentice Hall, 1933$) 21$.

[20] George A. Kennedy, trans. Aristotle on rhetoric: a theory of civic discourse (New York: Oxford UP, 1991$) 243$.

[21] Swami Vivekananda, What religion is? (Advaita Ashrama. Kolkata, 1972) 64.

[22] Swami Ramkrishnananda: his life and legacy, (Sri RamaKrishna Math, ISBN 978-81-7823-487-8) 165-169.

[22] T. A Sebeok (Ed), Style in language (Cambridge, Massachusetts: MIT Press, 1960) 217, $356,114$.

[23] W.H. Hudson, An outline history of English literature (B.J. Publications Pvt Ltd. New Delhi, 1961$) 185$. 